\title{
A national health facility survey of malaria infection among febrile patients in Kenya, 2014
}

Sophie Githinji ${ }^{*}$, Abdisalan M. Noor ${ }^{1,2}$, Josephine Malinga ${ }^{1}$, Peter M. Macharia', Rebecca Kiptui ${ }^{3}$, Ahmeddin $\mathrm{Omar}^{3}$, Kiambo Njagi ${ }^{3}$, Ejersa Waqo ${ }^{3}$ and Robert W. Snow ${ }^{1,2}$

\begin{abstract}
Background: The use of malaria infection prevalence among febrile patients at clinics has a potential to be a valuable epidemiological surveillance tool. However, routine data are incomplete and not all fevers are tested. This study was designed to screen all fevers for malaria infection in Kenya to explore the epidemiology of fever test positivity rates.

Methods: Random sampling was used within five malaria epidemiological zones of Kenya (i.e., high lake endemic, moderate coast endemic, highland epidemic, seasonal low transmission and low risk zones). The selected sample was representative of the number of hospitals, health centres and dispensaries within each zone. Fifty patients with fever presenting to each sampled health facility during the short rainy season were screened for malaria infection using a rapid diagnostic test (RDT). Details of age, pregnancy status and basic demographics were recorded for each patient screened.

Results: 10,557 febrile patients presenting to out-patient clinics at 234 health facilities were screened for malaria infection. 1633 (15.5\%) of the patients surveyed were RDT positive for malaria at 124 (53.0\%) facilities. Infection prevalence among non-pregnant patients varied between malaria risk zones, ranging from $0.6 \%$ in the low risk zone to $41.6 \%$ in the high lake endemic zone. Test positivity rates (TPR) by age group reflected the differences in the intensity of transmission between epidemiological zones. In the lake endemic zone, $6 \%$ of all infections were among children aged less than 1 year, compared to $3 \%$ in the coast endemic, 1\% in the highland epidemic zone, less than $1 \%$ in the seasonal low transmission zone and $0 \%$ in the low risk zone. Test positivity rate was $31 \%$ among febrile pregnant women in the high lake endemic zone compared to $9 \%$ in the coast endemic and highland epidemic zones, 3.2\% in the seasonal low transmission zone and zero in the low risk zone.

Conclusion: Malaria infection rates among febrile patients, with supporting data on age and pregnancy status presenting to clinics in Kenya can provide invaluable epidemiological data on spatial heterogeneity of malaria and serve as replacements to more expensive community-based infection rates to plan and monitor malaria control.
\end{abstract}

\section{Background}

The World Health Organization (WHO) recommends that all persons suspected of malaria should be examined for evidence of Plasmodium infection by either microscopy or rapid diagnostic tests (RDTs) before treatment is

\footnotetext{
*Correspondence: sophiegithinji@gmail.com

1 KEMRI-Wellcome Trust Collaborative Programme, Nairobi, Kenya Full list of author information is available at the end of the article
}

initiated [1]. RDTs for Plasmodium falciparum malaria are known to provide accurate diagnosis within a few minutes [2-5] and antimalarial treatment can be safely withheld if the result is negative [6]. Since the adoption of this global policy in 2010, the use of RDTs has doubled in Africa and increased the proportion of suspected malaria cases receiving a diagnostic test from 47 to $62 \%$ in 2013 [7]. Kenya adopted the policy on universal parasitological diagnosis on all cases suspected of malaria in 2010 [8] 
and in 2012, the National Malaria Control Programme (NMCP) embarked on a plan of rolling out RDTs to strengthen the capacity of malaria diagnostic services across the country [9].

The use of fever test positivity rates (TPR) has a long history as a measure of malaria risk in communities, most notably those in areas where the ambition is malaria elimination [10, 11]. More recently, health facility-based surveys of malaria infection prevalence in febrile patients have been used as part of the rapid analysis of malaria risks in urban settings in Angola, [12] Mozambique [13], Burkina Faso, Benin, Tanzania and Côte d'Ivoire [14]. They have also been used as part of national surveys of malaria epidemiology in Niger [15] and The Gambia [16], and as a means to operationally measure intervention effectiveness through sentinel based case-control studies in Benin [17] and Madagascar [18].

Quality of malaria diagnosis and treatment studies have been undertaken in Kenya on a bi-annual basis since 2010 [19-21]. These surveys have focused on describing routine clinical practices among febrile patients presenting to government out-patient departments and have highlighted that while the practice of parasitological diagnosis has increased significantly since 2010, testing rates for malaria have remained suboptimal. Over $30 \%$ of patients with fever were not tested with either an RDT or a blood slide in health facilities where diagnostics were available in September 2014, the month preceding the survey. This could be attributed to health worker clinical practices. Malaria case management trainings emphasizing on testing before treatment and routine supervisory visits have been recommended to further improve adherence to the policy [20]. The present study aimed to characterize the TPR of malaria in patients with reported fever presenting to clinics across Kenya to define the patterns of febrile infection rates nationwide as a potential epidemiological surveillance tool, not possible from routine data or from standard quality of care surveys.

\section{Methods}

\section{Study design and sampling}

A national cross-sectional survey was undertaken at public health facilities sampled according to malaria endemicity zones. A stratified sampling frame was developed based upon the universe of 4242 geo-coded public health facilities offering out-patient general clinical services $[22,23]$ within five malaria epidemiological zones. These zones have been used by the Ministry of Health for over 40 years $[24,25]$ and refined more recently to provide targeted malaria control services [22, 26, 27]. These malaria zones cover the high, stable perennial transmission areas of western Kenya around Lake Victoria (lake endemic), moderate, seasonal transmission areas along the Kenyan coast (Coast endemic), acutely seasonal, low transmission areas of northern, eastern and southeastern Kenya (seasonal low transmission), the unstable, variable transmission areas of the highlands west of the Rift Valley (highland epidemic) and the central highlands including areas around Nairobi traditionally considered either free of malaria or of exceptionally low transmission (low risk).

The sample size was determined based on the proportion of positive $P$. falciparum obtained during the RDT piloting period from 2007 to 2010, aggregated by endemicity zone. This proportion was used to compute the number of fever cases necessary to provide the estimated malaria case load per zone. A spatial sampling design tool was then used to draw a random spatially weighted sample proportionate to number and types of health facilities within each zone (Fig. 1). With a target of at least 50 febrile patients per facility [28], 234 public health facilities were required across all zones.

\section{Data collection}

The survey was conducted in October and November 2014, coinciding with the short rainy season. Seventysix senior laboratory technologists underwent a two day training workshop on survey procedures and a refresher course on how to diagnose malaria using Carestart HRP2 P. falciparum RDT. Each survey technologist was based at a sampled facility for a maximum of 5 days to recruit all out-patients reporting any history of fever in the last $48 \mathrm{~h}$ identified by clinicians who screened all presenting patients on the survey days. Patients with a history of fever in the last $48 \mathrm{~h}$, who had not sought anti-malarial treatment before attending the facility were asked to provide informed consent. For each consenting participant, information was collected on basic demographics and usual residence. For women aged between 15 and 49 years, additional information on pregnancy status was recorded. Each patient provided a single finger-prick blood sample for the malaria RDT. The RDT results were read as per the manufacturer's instructions and recorded separately on the patient's questionnaire. Test results were then passed on to the health care provider to use in managing the patient.

\section{Data management and analysis}

Data entry was undertaken in Access (Microsoft, USA) using customized data entry screens with inbuilt consistency checks. Data analysis was performed using STATA, version 12 (StataCorp, College Station, Texas, USA). The primary outcome variable was prevalence of malaria calculated as a percentage of the total number of people tested that had RDT positive results. Analysis was undertaken overall and per malaria risk zone. 


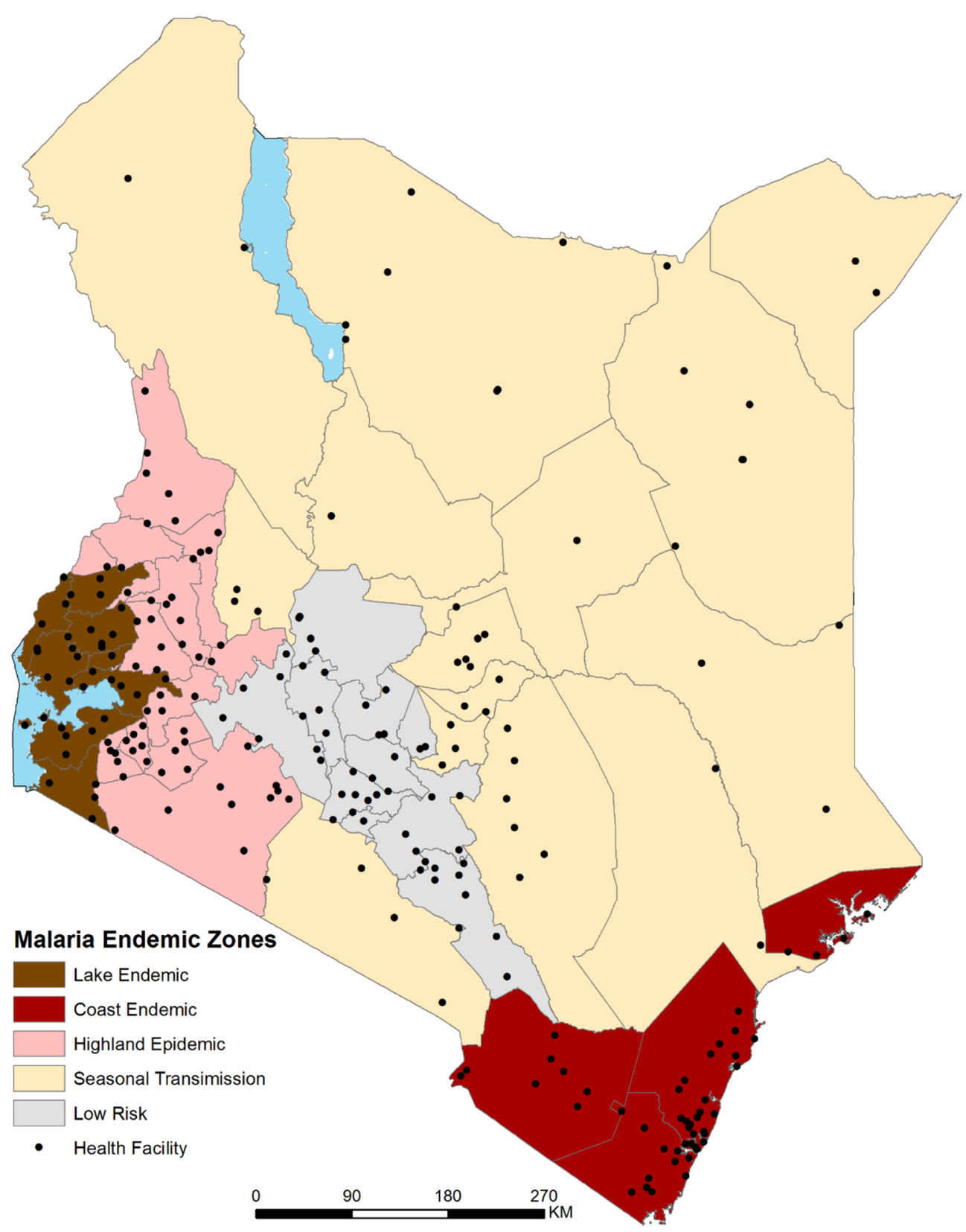

Fig. 1 Location of sampled health facilities across five malaria endemicity zones in Kenya

\section{Results}

Sample description

The survey was conducted at all 234 sampled health facilities, comprising of 23 hospitals, 99 health centres and 112 dispensaries (Table 1). A total of 58,080 out-patients presented at the health facilities during the survey days and $12,913(22.2 \%)$ reported a history of fever within the last 48 h. 10,557 consenting febrile out-patients without previous anti-malarial treatment were enrolled into the survey. Thirteen patients, all of them with negative RDT test results, were excluded from the analysis because of missing data on age. The background characteristics of the surveyed patients by malaria risk zone are shown in Table 1.

\section{Prevalence of malaria by malaria zone and age}

Overall, 1633 (15.5\%) of the febrile patients surveyed were RDT positive for malaria at 124 (53.0\%) facilities. Among non-pregnant patients 1600 (15.8\%) infections were detected among 10,112 patients with a recent 
Table 1 Background characteristics of 10,544 surveyed patients from 234 public health facilities in Kenya 2014

\begin{tabular}{|c|c|c|c|c|c|c|}
\hline $\begin{array}{l}\text { Background } \\
\text { characteristic }\end{array}$ & $\begin{array}{l}\text { Lake endemic } \\
\mathrm{N}=1847\end{array}$ & $\begin{array}{l}\text { Coast endemic } \\
\mathrm{N}=2163\end{array}$ & $\begin{array}{l}\text { Highland epidemic } \\
\mathrm{N}=2213\end{array}$ & $\begin{array}{l}\text { Seasonal low } \\
\text { transmission } \\
\mathrm{N}=2247\end{array}$ & $\begin{array}{l}\text { Low risk } \\
\mathrm{N}=2074\end{array}$ & $\begin{array}{l}\text { Total } \\
N=10,544\end{array}$ \\
\hline \multicolumn{7}{|l|}{ Patients } \\
\hline \multicolumn{7}{|l|}{ Age (years) } \\
\hline$<5$ & 606 & 794 & 634 & 471 & 534 & 3039 \\
\hline $5-14$ & 525 & 581 & 524 & 461 & 410 & 2501 \\
\hline$\geq 15$ & 716 & 788 & 1055 & 1315 & 1130 & 5004 \\
\hline Male & 774 & 956 & 928 & 929 & 787 & 4374 \\
\hline Female & 1073 & 1207 & 1285 & 1318 & 1287 & 6170 \\
\hline Pregnant & 51 & 77 & 70 & 126 & 108 & 432 \\
\hline \multicolumn{7}{|l|}{ Facility type } \\
\hline Total facilities & 37 & 47 & 50 & 54 & 46 & 234 \\
\hline Hospital & 5 & 5 & 3 & 5 & 5 & 23 \\
\hline Health centre & 12 & 11 & 22 & 27 & 27 & 99 \\
\hline Dispensary & 20 & 31 & 25 & 22 & 14 & 112 \\
\hline
\end{tabular}

history of fever. As would be expected, infection prevalence among non-pregnant patients varied between malaria risk zones, ranging from $0.6 \%$ in the Low risk zone to $41.6 \%$ in the high Lake endemic zone (Table 2). At $110(47 \%)$ facilities, no patients were found to be RDT positive during the survey, of these 38 (34.5\%) were located in the low risk zone, and the proportion of facilities without any RDT positive febrile patients followed a similar pattern to the fraction of positive patients in each malaria zone (Table 2).

The age pattern of infection among non-pregnant patients across all malaria zones followed a similar pattern, with low infection rates in febrile infants rising to the highest infection rates among febrile children aged 5-9 and/or 10-14 years, then declining through young adulthood (Fig. 2). There were, however, important differences in age positivity between malaria zones. The typical age-pattern of infection was much less pronounced in the very low risk zone, with risks of infection among fevers being similar across most age groups outside of infancy. Infants in the lake endemic zone had the highest rates of infection compared to all the other endemicity zones (Fig. 2). In the lake endemic zone, $6 \%$ of all infections were among children aged less than 1 year, compared to $3 \%$ in the coast endemic and highland epidemic zone and less than $1 \%$ in the low risk zone and $0 \%$ in the exceptionally low risk zone (Table 2).

\section{Malaria infection among febrile pregnant women}

A total of 432 women with a recent history of fever reported being pregnant at the time of the consultation, of whom 33 (7.6\%) were RDT positive. Sixteen of these infections were identified in the lake endemic zone among 51 pregnant women (prevalence 31.4\%). Infection prevalence among febrile pregnant women was less than $10 \%$ in the coast endemic and highland epidemic zone, $3.2 \%$ in the seasonal low transmission zone and zero in the exceptionally low risk zone (Table 2).

\section{Discussion}

The present study was not designed to compare the direct congruence between fever test positivity rates (TPR) at health facilities and the prevalence of malaria infection among communities served by these facilities. Rather, a comparison is made between RDT positivity among all fevers presenting to facilities against the operational definitions of malaria zones used by the NMCP to define intervention options for control. The overall TPR (Table 2), and the age-patterns of TPR recorded at public health facilities (Fig. 2), varied between malaria endemic zones in ways which could be used to operationally define malaria risk in communities and importantly how these age-specific metrics change between seasons, between years and overtime as interventions to prevent malaria exposure increase in coverage. The traditional high transmission areas around Lake Victoria showed the highest overall TPR, the highest rates of infection among febrile infants and the highest rates among febrile pregnant women (Table 2; Fig. 2). Areas that the Kenyan Ministry of Health regards as having intermediate transmission along the Kenyan coast or in the epidemic prone areas of the highlands correspond to lower levels of overall TPR with fever infection rates less concentrated in the youngest children and intermediate levels of infection among febrile pregnant women (Table 2; Fig. 2). Areas where transmission has been historically very low are 
Table 2 RDT prevalence of infection among patients with reported fever in last $\mathbf{4 8} \mathbf{~}$ at public health facilities in Kenya 2014 - n/N (\%) [95\% confidence interval]

\begin{tabular}{|c|c|c|c|c|c|c|}
\hline & Lake endemic & Coast endemic & $\begin{array}{l}\text { Highland } \\
\text { epidemic }\end{array}$ & $\begin{array}{l}\text { Seasonal low } \\
\text { transmission }\end{array}$ & Low risk & Total \\
\hline Mean $^{\mathrm{a}}$ & $41.30 \%$ & $21.90 \%$ & $13.10 \%$ & $3.80 \%$ & $0.60 \%$ & $14.70 \%$ \\
\hline Median & $46.00 \%$ & $10.00 \%$ & $2.00 \%$ & $0.00 \%$ & $0.00 \%$ & $2.00 \%$ \\
\hline IQR & $31.0-56.0 \%$ & $2.1-46.0 \%$ & $0.0-19.0 \%$ & $0.0-2.3 \%$ & $0.0-0.0 \%$ & $0.0-22.1 \%$ \\
\hline $\begin{array}{l}\text { Proportion of } \\
\text { facilities without } \\
\text { any RDT positive } \\
\text { fevers }\end{array}$ & 0/37 (0\%) & $10 / 47(21.3 \%)$ & $22 / 50(44.0 \%)$ & 40/54 (74.1\%) & $38 / 46(82.6 \%)$ & 110/234 (47.0\%) \\
\hline \multicolumn{7}{|c|}{ Percentage positive by age group } \\
\hline$<1$ year & $\begin{array}{c}42 / 131(32.1 \%) \\
{[24.2-41.1]}\end{array}$ & $\begin{array}{c}6 / 176(3.4 \%) \\
{[1.3-9.1]}\end{array}$ & $\begin{array}{c}9 / 122(7.4 \%) \\
{[3.5-14.8]}\end{array}$ & $\begin{array}{c}2 / 108(1.9 \%) \\
{[0.4-7.6]}\end{array}$ & 0/147 (0\%) & $\begin{array}{c}59 / 684(8.6 \%) \\
{[6.2-11.9]}\end{array}$ \\
\hline $1-4$ years & $\begin{array}{l}\text { 253/476 (53.2\%) } \\
{[44.0-62.1]}\end{array}$ & $\begin{array}{c}133 / 618(21.5 \%) \\
{[13.9-31.6]}\end{array}$ & $\begin{array}{c}75 / 512(14.6 \%) \\
{[8.5-24.1]}\end{array}$ & $\begin{array}{c}15 / 363(4.1 \%) \\
{[1.3-12.5]}\end{array}$ & $\begin{array}{c}4 / 387(1.0 \%) \\
{[0.4-2.6]}\end{array}$ & $\begin{array}{c}480 / 2356(20.4 \%) \\
{[16.5-25.0]}\end{array}$ \\
\hline $5-9$ years & $\begin{array}{c}186 / 286(65.0 \%) \\
{[57.5-71.9]}\end{array}$ & $\begin{array}{c}\text { 146/357 (40.9\%) } \\
{[31.0-51.6]}\end{array}$ & $\begin{array}{c}66 / 284(23.2 \%) \\
{[13.5-37.1]}\end{array}$ & $\begin{array}{c}13 / 264(4.9 \%) \\
{[1.6-14.5]}\end{array}$ & 0/247 (0\%) & $\begin{array}{c}411 / 1438(28.6 \%) \\
{[23.5-34.3]}\end{array}$ \\
\hline $10-14$ years & $\begin{array}{c}133 / 239(55.6 \%) \\
{[46.6-64.4]}\end{array}$ & $\begin{array}{c}92 / 224(41.1 \%) \\
{[29.3-54.0]}\end{array}$ & $\begin{array}{c}60 / 240(25.0 \%) \\
{[14.2-40.1]}\end{array}$ & $\begin{array}{c}12 / 197(6.1 \%) \\
{[2.2-15.7]}\end{array}$ & 0/163 (0\%) & $\begin{array}{l}297 / 1063(27.9 \%) \\
{[22.7-33.9]}\end{array}$ \\
\hline $\begin{array}{l}\text { 15+ (non-preg- } \\
\text { nant) }\end{array}$ & $\begin{array}{c}134 / 664(20.2 \%) \\
{[15.7-25.6]}\end{array}$ & $\begin{array}{c}93 / 711(13.1 \%) \\
{[8.9-18.7]}\end{array}$ & $\begin{array}{c}88 / 985(8.9 \%) \\
{[5.3-14.8]}\end{array}$ & $\begin{array}{l}31 / 1189(2.6 \%) \\
{[1.3-5.1]}\end{array}$ & $\begin{array}{c}\text { 7/1022 (0.7\%) } \\
{[0.3-1.4]}\end{array}$ & $\begin{array}{l}353 / 4571(7.7 \%) \\
{[6.2-9.6]}\end{array}$ \\
\hline $\begin{array}{l}\text { TPR for all } \\
\text { non-pregnant } \\
\text { patients }\end{array}$ & $\begin{array}{l}\text { 748/1796 (41.6\%) } \\
{[36.1-47.4]}\end{array}$ & $\begin{array}{c}470 / 2086(22.5 \%) \\
{[16.0-30.8]}\end{array}$ & $\begin{array}{l}\text { 298/2143 (13.9\%) } \\
{[8.5-21.9]}\end{array}$ & $\begin{array}{l}\text { 73/2121 (3.4\%) } \\
{[1.6-7.4]}\end{array}$ & $\begin{array}{l}11 / 1966(0.6 \%) \\
{[0.3-1.1]}\end{array}$ & $\begin{array}{c}1600 / 10,112(15.8 \%) \\
{[13.0-19.1]}\end{array}$ \\
\hline Pregnant women & $\begin{array}{c}16 / 51(31.4 \%) \\
{[17.6-49.4]}\end{array}$ & $\begin{array}{r}7 / 77(9.1 \%) \\
{[3.8-20.0]}\end{array}$ & $\begin{array}{r}6 / 70(8.6 \%) \\
{[3.6-18.9]}\end{array}$ & $\begin{array}{c}4 / 126(3.2 \%) \\
{[1.2-7.4]}\end{array}$ & 0/108 (0\%) & $\begin{array}{c}33 / 432(7.6 \%) \\
{[5.1-11.4]}\end{array}$ \\
\hline \multicolumn{7}{|c|}{ Percentage of positives aged } \\
\hline$<1$ & $\begin{array}{c}42 / 764(5.5 \%) \\
{[3.9-7.6]}\end{array}$ & $\begin{array}{c}6 / 477(1.3 \%) \\
{[0.5-3.3]}\end{array}$ & $\begin{array}{l}9 / 304(3.0 \%) \\
{[1.4-6.0]}\end{array}$ & $\begin{array}{c}2 / 77(2.6 \%) \\
{[0.9-7.5]}\end{array}$ & $0(0 \%)$ & $\begin{array}{l}\text { 59/1633 (3.6\%) } \\
{[2.7-4.8]}\end{array}$ \\
\hline$<5$ & $\begin{array}{c}\text { 295/764 (38.6\%) } \\
{[33.0-44.6]}\end{array}$ & $\begin{array}{c}\text { 139/477 (29.1\%) } \\
{[23.2-36.0]}\end{array}$ & $\begin{array}{c}84 / 304(27.6 \%) \\
{[23.2-32.5]}\end{array}$ & $\begin{array}{c}17 / 77(22.1 \%) \\
{[10.8-39.8]}\end{array}$ & $\begin{array}{r}4 / 11(36.4 \%) \\
{[19.5-57.5]}\end{array}$ & $\begin{array}{c}\text { 539/1633 (33.0\%) } \\
{[29.6-36.6]}\end{array}$ \\
\hline $\begin{array}{l}\text { RDT Test Positivity } \\
\text { Rate }\end{array}$ & $\begin{array}{l}\text { 764/1847 (41.4\%) } \\
{[35.8-47.1]}\end{array}$ & $\begin{array}{c}477 / 2163(22.1 \%) \\
{[15.6-30.2]}\end{array}$ & $\begin{array}{l}\text { 304/2213 (13.7\%) } \\
{[8.4-21.6]}\end{array}$ & $\begin{array}{c}77 / 2247(3.4 \%) \\
{[1.6-7.4]}\end{array}$ & $\begin{array}{c}11 / 2074(0.5 \%) \\
{[0.3-1.1]}\end{array}$ & $\begin{array}{c}1633 / 10,544(15.5 \%) \\
{[12.7-18.6]}\end{array}$ \\
\hline
\end{tabular}

a Refers to the mean between health facilities in each zone

characterized, as one might expect, with very low levels of infection among fevers presenting to clinic in all age groups or no infection reported in infants or pregnant women (Fig. 2).

These patterns of infection in fevers across the varied epidemiology of Kenya are important because the default for classifications of malaria risk zones in Africa continues to be community-based malaria infection cross-sectional surveys [29]. Modelled and mapped community-based parasite prevalence is used for planning control across Africa [29-31] and to subsequently model presumed malaria burdens [7]. Surveys among asymptomatic individuals at the community level are expensive, even when constrained to simpler sampling frames such as school children [32]. Conversely, the testing of all fevers at health facilities should be routine [8] and in theory these data should be available at no additional cost. Routine continuous data from facilities have the additional advantage of covering every month of every year, as opposed to single snap shot data from one off malaria indicator surveys. If data were available with enough collateral information on age, pregnancy status and facilities were geo-coded, such data would provide invaluable epidemiological evidence for programmes to compute spatial epidemiological risks to plan and monitor control operations and ultimately migrate into a surveillance system able to identify "hot spots" for targeted disease control [33] and be useful to exclude malaria risks (for example by examining infant or pregnancy fever infection risks, Table 2).

In The Gambia a more direct comparison of malaria infection rates among fevers at clinics and corresponding infection and serological rates at matched communities showed very similar age-patterns of risk and spatial heterogeneity [16]. A study of infection prevalence among fevers at clinics, similar to the study presented here, undertaken across Niger between 2009 and 2010, showed a congruence with the established bio-climatic zones and 

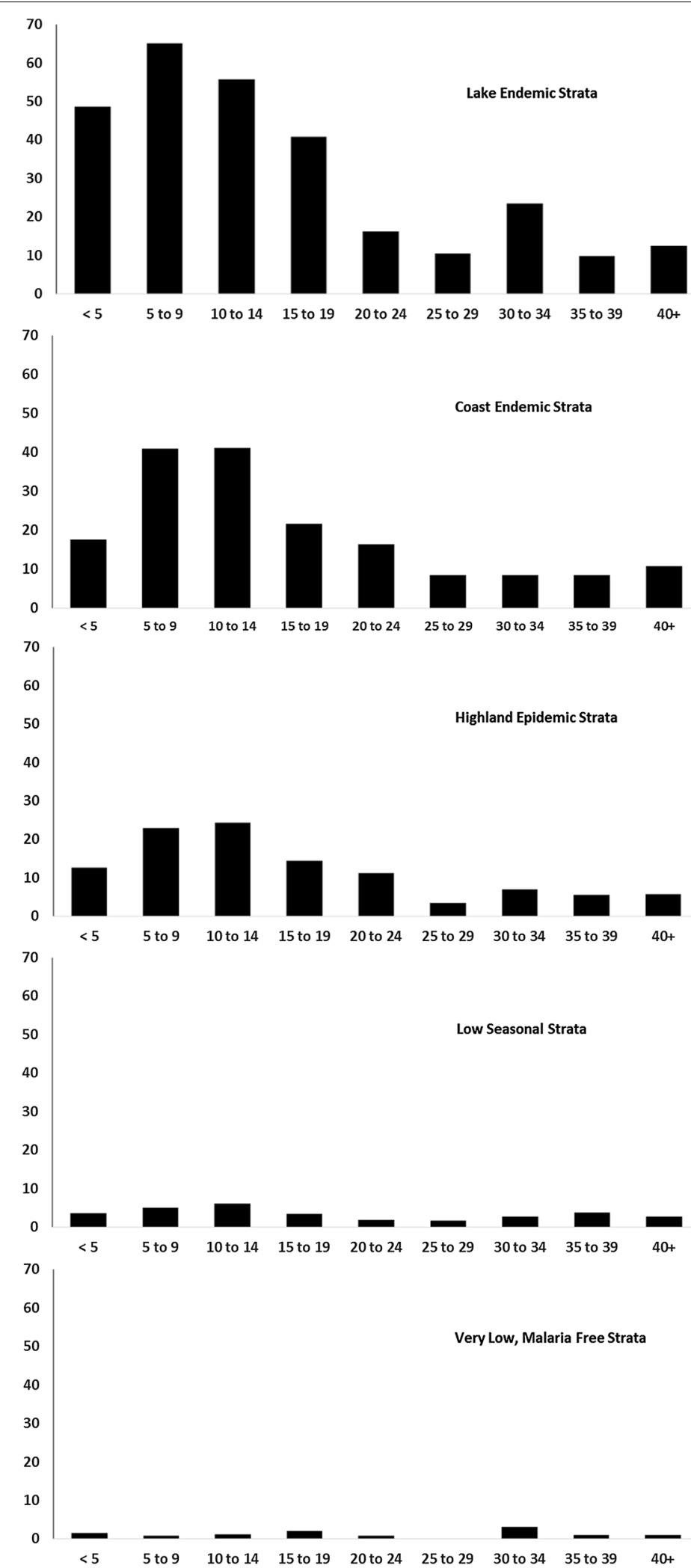

Fig. 2 Age-specific test positivity rates among febrile patients attending out-patient clinics in October-November 2014 in five malaria endemicity zones 
seasonality used by the Niger National Malaria Control Programme to target malaria control [15]. Importantly, the Niger study highlighted the inadequacy of routine data from the health information system which included those suspected and not confirmed with malaria and the incomplete nature of data on how many individuals were tested for malaria [15].

There have been significant investments across Africa, including Kenya, to improve the ability of routine services to accurately record health information in a timely fashion through the District Health Information System 2.0 (DHIS2.0) or the Integrated Disease Surveillance Reporting System (IDSR) [34-36]. However, the detail, completeness and coverage of these data necessary to provide reliable epidemiological data for malaria programmes remains poor [37]. In Kenya, not all fevers are tested [20], the numbers of people tested is not always recorded, data are aggregated over districts, age groups, and time losing the granularity of information on age, seasonality, location and pregnancy status [38].

Interestingly, there was a high frequency of infection among children aged 10-14 years of age presenting with fever to clinics in all endemicity zones (Fig. 2). Recent studies across different settings have reported a gradual shifting of peak parasite prevalence of malaria from younger to older children [39-41]. This has been attributed to enhanced control efforts that have resulted in children acquiring immunity to malaria more gradually than in the past and clinical attacks occurring in schoolage children more frequently [42]. This school-aged population are neglected from most child clinic services and community-based vector control programmes [4244 , however they are an ever important source of clinical malaria infections that should be highlighted during future clinical training programmes.

The default diagnostic test used in the present study was RDTs, these are far more ubiquitous than microscopy in Kenya [21] are available at all levels of the health sector and are subject to less between observer variability [2]. Patients who reported taking any anti-malarial treatment in the 2 weeks preceding the survey were excluded from the study because of the well-known persistence of HRP2 antigenaemia after treatment [45]. However, a recent study in Uganda reported a much longer HRP2 persistence period extending to a median of 35 to $\geq 42$ days after treatment [46]. It is, therefore, possible that patients found positive in this survey, especially in the high endemic areas, may have been due to persistent HRP2 antigenaemia. However, the associated risk of overtreatment of uninfected cases is considered more acceptable in malaria endemic zones than taking the risk of failing to detect cases. Recently, there has been reports of deletion of HRP2 gene which may lead to false RDT negative results $[47,48]$. However, studies conducted in Africa showed HRP2 deletion in very small numbers of parasite isolates $[49,50]$, hence highly unlikely that the phenomenon may have influenced the results of this survey. The aim of the survey reported here was not to measure "true" prevalence of malaria in febrile populations, through expert microscopy or polymerase chain reaction (PCR) assays, but emulate what might be routinely available if collected on all febrile patients. This study was limited in that it was restricted to only one time of the year and, therefore, not representative of periods of low transmission. Nor did the study examine the effects of residence and travel time to facilities that may independently of age affect TPR [51]. A more detailed analysis of pockets of high transmission within broad ecological zones would have required larger facility sample sizes, beyond the scope of the present study. Pregnancy status was only asked about and no tests were done. This could have caused certain underreporting of malaria infection in pregnancy. Finally, it would have been interesting to examine a more direct spatial and temporal matched congruence between facility-based TPR and communitybased parasite prevalence across the country. Such studies would enable a calibration between two dominant measures used in malaria risk mapping and a more reliable pathway to estimating the relationships between combinations of TPR and community based prevalence with disease incidence [52-54].

\section{Conclusions}

Malaria infection rates among febrile patients presenting to clinics in Kenya could provide invaluable epidemiological data on the seasonal, temporal and spatial heterogeneity of malaria and serve as replacements to more expensive community-based infection rates to plan and monitor malaria control. However, for these data to be of use for the national malaria control programme, increased testing rates, more granular information on patient level data and improved coverage of routine data are required.

\section{Authors' contributions \\ SG coordinated the survey, analyzed the data and drafted the manuscript. JM and PM contributed to data analysis. JM helped in survey coordination. RK, $\mathrm{AO}, \mathrm{KN}, \mathrm{EW}$ contributed to the implementation of the survey. AMN and RWS participated in study design, provided guidance on data analysis and drafting the manuscript. All authors read and approved the final manuscript.}

\section{Author details}

${ }^{1}$ KEMRI-Wellcome Trust Collaborative Programme, Nairobi, Kenya. ${ }^{2}$ Centre for Tropical Medicine and Global Health, Nuffield Department of Clinical Medicine, University of Oxford, Oxford, UK. ${ }^{3}$ National Malaria Control Programme, Ministry of Health, Nairobi, Kenya.

\section{Acknowledgements}

The authors are grateful to Professor Dejan Zurovac for comments on an earlier draft of the manuscript. In addition, the authors are grateful to all 
medical laboratory technologists, data entry clerks and research assistants who participated in the data collection exercise and to the County Health Executives and Malaria Control Coordinators who supported the implementation of the survey. Finally, we thank all patients and caregivers of children who participated in the survey. This paper is published with the permission of the Director of KEMRI.

\section{Competing interests}

The authors declare that they have no competing interests.

\section{Availability of data and material}

Data and figures can be made available from the authors via corresponding author.

\section{Consent for publication}

All patients who participated in the survey or their guardians gave written consent to participate and to publication of the findings.

\section{Ethical approval and consent to participate}

Ethical approval was granted by KEMRI Ethical Review Board (SSC No. 2595). The survey staff explained the study to all eligible patients or their guardians including publication of study findings. Written consent to participate in the survey and to publish the findings was sought from each enrolled patient or their guardian.

\section{Funding}

Funding for this project was provided through the World Health Organization by Department for International Development (DFID), United Kingdom (\#B9R002). SG is supported by Grants from the Wellcome Trust (\#95063) and the Medical Research Council-DFID-Wellcome Trust (\#MR/K007351/1). AMN is supported as a Wellcome Trust Intermediary Fellowship (\#095127). RWS is supported by the Wellcome Trust as Principal Research Fellow (\#103602).

Received: 30 September 2016 Accepted: 24 November 2016 Published online: 08 December 2016

\section{References}

1. WHO. Guidelines for the treatment of malaria, 2nd edn. Geneva: World Health Organization; 2010.

2. Moody A. Rapid diagnostic tests for malaria parasites. Clin Microbiol Rev. 2002;15:66-78.

3. Murray CK, Gasser RA Jr, Magill AJ, Miller RS. Update on rapid diagnostic testing for malaria. Clin Microbiol Rev. 2008;21:97-110.

4. de Oliveira AM, Skarbinski J, Ouma PO, Kariuki S, Barnwell JW, Otieno K, et al. Performance of malaria rapid diagnostic tests as part of routine malaria case management in Kenya. Am J Trop Med Hyg. 2009:80:470-4.

5. Abba K, Deeks JJ, Olliaro P, Naing CM, Jackson SM, Takwoingi Y, et al. Rapid diagnostic tests for diagnosing uncomplicated $P$. falciparum malaria in endemic countries. Cochrane Database Syst Rev. 2011. doi:10.1002/14651858.CD008122.pub2.

6. d'Acremont V, Malila A, Swai N, Tillya R, Kahama Maro J, Lengeler C, et al. Withholding antimalarials in febrile children who have a negative result for a rapid diagnostic test. Clin Infect Dis. 2010;51:506-11.

7. WHO. World Malaria Report 2014. Geneva: World Health Organization; 2014

8. Ministry of Public Health and Sanitation. National guidelines for the diagnosis, treatment and prevention of malaria in Kenya. Nairobi: Division of Malaria Control, Ministry of Public Health and Sanitation; 2010.

9. Ministry of Public Health and Sanitation. Use of rapid diagnostic tests to improve malaria diagnosis and fever case management: implementation plan for scale up in Kenya; 2012.

10. Pull JH. Malaria surveillance methods, their uses and limitations. Am J Trop Med Hyg. 1972;21:651-7.

11. Hay SI, Smith DL, Snow RW. Measuring malaria endemicity from intense to interrupted transmission. Lancet Infect Dis. 2008;8:369-78.

12. Thwing Jl, Mihigo J, Fernandes AP, Saute F, Ferreira C, Fortes F, et al. How much malaria occurs in urban Luanda, Angola? A health facility-based assessment. Am J Trop Med Hyg. 2009;80:487-91.
13. Macedo de Oliveira A, Mutemba R, Morgan J, Streat E, Roberts J, Menon $\mathrm{M}$, et al. Prevalence of malaria among patients attending public health facilities in Maputo City, Mozambique. Am J Trop Med Hyg. 2011:85:1002-7.

14. Wang SJ, Lengeler C, Smith TA, Vounatsou P, Cisse G, Diallo DA, et al. Rapid urban malaria appraisal (RUMA) in sub-Saharan Africa. Malar J. 2005;4:40.

15. Doudou MH, Mahamadou A, Ouba I, Lazoumar R, Boubacar B, Arzika I, et al. A refined estimate of the malaria burden in Niger. Malar J. 2012;11:89.

16. Oduro AR, Bojang KA, Conway DJ, Corrah T, Greenwood BM, Schellenberg $\mathrm{D}$. Health centre surveys as a potential tool for monitoring malaria epidemiology by area and over time. PLoS ONE. 2011;6:e26305.

17. Damien GB, Djenontin A, Chaffa E, Yamadjako S, Drame PM, Ndille EE, et al. Effectiveness of insecticidal nets on uncomplicated clinical malaria: a case-control study for operational evaluation. Malar J. 2016;15:102.

18. Kesteman T, Randrianarivelojosia M, Raharimanga V, Randrianasolo L, Piola P, Rogier C. Effectiveness of malaria control interventions in Madagascar: a nationwide case-control survey. Malar J. 2016;15:83.

19. Nyandigisi A, Memusi D, Mbithi A, Ang'wa N, Shieshia M, Muturi A, et al. Malaria case-management following change of policy to universal parasitological diagnosis and targeted artemisinin-based combination therapy in Kenya. PLoS ONE. 2011;6:e24781.

20. Zurovac D, Githinji S, Memusi D, Kigen S, Machini B, Muturi A, et al. Major improvements in the quality of malaria case-management under the "test and treat" policy in Kenya. PLoS ONE. 2014;9:e92782.

21. Machini B, Nyandigisi A, Kigen S, Memusi D, Kimbui R, Malinga J, et al. Monitoring outpatient malaria case management under the 2010 diagnostic and treatment policy in Kenya-Progress 2010-2015. National Malaria Control Programme, Ministry of Health; 2015.

22. Noor AM, Gething PW, Alegana VA, Patil AP, Hay SI, Muchiri E, et al. The risks of malaria infection in Kenya in 2009. BMC Infect Dis. 2009;9:180.

23. Master health facility list. http://ehealth.or.ke/facilities/.

24. Roberts JMD. Malaria in malaria. In: Health and disease in Kenya. Nairobi: East African Literature Bureau; 1974. p. 305-317.

25. Ministry of Health Kenya. Kenya national plan of action for malaria control: five-year plan and budget. Nairobi: Ministry of Health; 1992.

26. Ministry of Public Health and Sanitation. National malaria strategy 2009-2017. Nairobi: Division of Malaria Control, Ministry of Public Health and Sanitation; 2009.

27. Noor A, Kinyoki D, Ochieng J, Kabaria C, Alegana V, Otieno V, et al. The epidemiology and control profile of malaria in Kenya: reviewing the evidence to guide the future vector control. Division of Malaria Control, Ministry of Public Health and Sanitation \& Malaria Public Health Department, KEMRIWelcome Trust-University of Oxford Research Programme; 2012.

28. Gregory RD, Blackburn TM. Parasite prevalence and host sample size. Parasitol Today. 1991;7:316-8.

29. Snow RW, Noor AM. Malaria risk mapping in Africa: The historical context to the Information for Malaria (INFORM) project. In: Working paper in support of the INFORM Project funded by the Department for International Development and the Wellcome Trust, Nairobi; 2015.

30. Omumbo JA, Noor AM, Fall IS, Snow RW. How well are malaria maps used to design and finance malaria control in Africa? PLoS ONE. 2013;8:e53198.

31. Noor AM, Kinyoki DK, Mundia CW, Kabaria CW, Mutua JW, Alegana VA et al. The changing risk of Plasmodium falciparum malaria infection in Africa: 2000-10: a spatial and temporal analysis of transmission intensity. Lancet. 2014;383:1739-47.

32. Gitonga CW, Karanja PN, Kihara J, Mwanje M, Juma E, Snow RW, et al. Implementing school malaria surveys in Kenya: towards a national surveillance system. Malar J. 2010;9:306.

33. Bousema T, Griffin JT, Sauerwein RW, Smith DL, Churcher TS, Takken W, et al. Hitting hotspots: spatial targeting of malaria for control and elimination. PLoS Med. 2012;9:e1001165.

34. Perry HN, McDonnell SM, Alemu W, Nsubuga P, Chungong S, Otten MW $\mathrm{Jr}$, et al. Planning an integrated disease surveillance and response system: a matrix of skills and activities. BMC Med. 2007;5:24.

35. WHO. Country health information systems: a review of the current situation and trends. Geneva: World Health Organization; 2011.

36. Mutale W, Chintu N, Amoroso C, Awoonor-Williams K, Phillips J, Baynes C, et al. Improving health information systems for decision making across five sub-Saharan African countries: implementation strategies from the African Health Initiative. BMC Health Serv Res. 2013;13(Suppl 2):S9. 
37. Rowe AK, Kachur SP, Yoon SS, Lynch M, Slutsker L, Steketee RW. Caution is required when using health facility-based data to evaluate the health impact of malaria control efforts in Africa. Malar J. 2009;8:209.

38. Githinji S, Malinga J, Waqo E, Soti D, Rono J, et al. Exploring routinely reported malaria data in Kenya; a data quality assessment. Nairobi: National Malaria Control programe, Ministry of Health; 2016.

39. Oduro AR, Conway DJ, Schellenberg D, Satoguina J, Greenwood BM Bojang KA. Seroepidemiological and parasitological evaluation of the heterogeneity of malaria infection in the Gambia. Malar J. 2013;12:222.

40. Farnert A, Yman V, Homann MV, Wandell G, Mhoja L, Johansson M, et al. Epidemiology of malaria in a village in the Rufiji River Delta, Tanzania: declining transmission over 25 years revealed by different parasitological metrics. Malar J. 2014;13:459.

41. Trape JF, Tall A, Sokhna C, Ly AB, Diagne N, Ndiath O, et al. The rise and fall of malaria in a West African rural community, Dielmo, Senegal, from 1990 to 2012: a 22 year longitudinal study. Lancet Infect Dis. 2014;14:476-88.

42. Nankabirwa J, Brooker SJ, Clarke SE, Fernando D, Gitonga CW, Schellenberg D, et al. Malaria in school-age children in Africa: an increasingly important challenge. Trop Med Int Health. 2014;19:1294-309.

43. Gitonga CW, Edwards T, Karanja PN, Noor AM, Snow RW, Brooker SJ. Plasmodium infection, anaemia and mosquito net use among school children across different settings in Kenya. Trop Med Int Health. 2012;17:858-70.

44. Noor AM, Kirui VC, Brooker SJ, Snow RW. The use of insecticide treated nets by age: implications for universal coverage in Africa. BMC Public Health. 2009;9:369.

45. Abeku TA, Kristan M, Jones C, Beard J, Mueller DH, Okia M, et al. Determinants of the accuracy of rapid diagnostic tests in malaria case management: evidence from low and moderate transmission settings in the East African highlands. Malar J. 2008;7:202.
46. Grandesso F, Nabasumba C, Nyehangane D, Page AL, Bastard M, De Smet $M$, et al. Performance and time to become negative after treatment of three malaria rapid diagnostic tests in low and high malaria transmission settings. Malar J. 2016;15:496.

47. Murillo Solano C, Akinyi Okoth S, Abdallah JF, Pava Z, Dorado E, Incardona $\mathrm{S}$, et al. Deletion of Plasmodium falciparum histidine-rich protein 2 (pfhrp2) and histidine-rich protein 3 (pfhrp3) genes in Colombian parasites. PLoS ONE. 2015;10:e0131576.

48. Bharti PK, Chandel HS, Ahmad A, Krishna S, Udhayakumar V, Singh N. Prevalence of pfhrp2 and/or pfhrp3 gene deletion in Plasmodium falciparum population in eight highly endemic states in India. PLoS ONE. 2016;11:e0157949.

49. Koita OA, Doumbo OK, Ouattara A, Tall LK, Konare A, Diakite M, et al. Falsenegative rapid diagnostic tests for malaria and deletion of the histidinerich repeat region of the hrp2 gene. Am J Trop Med Hyg. 2012;86:194-8.

50. Wurtz N, Fall B, Bui K, Pascual A, Fall M, Camara C, et al. Pfhrp2 and pfhrp3 polymorphisms in Plasmodium falciparum isolates from Dakar, Senegal: impact on rapid malaria diagnostic tests. Malar J. 2013;12:34.

51. Francis D, Gasasira A, Kigozi R, Kigozi S, Nasr S, Kamya MR, et al. Health facility-based malaria surveillance: the effects of age, area of residence and diagnostics on test positivity rates. Malar J. 2012;11:229.

52. Jensen TP, Bukirwa H, Njama-Meya D, Francis D, Kamya MR, Rosenthal $P J$, et al. Use of the slide positivity rate to estimate changes in malaria incidence in a cohort of Ugandan children. Malar J. 2009;8:213.

53. Yukich J, Briet O, Bretscher MT, Bennett A, Lemma S, Berhane Y, et al. Estimating Plasmodium falciparum transmission rates in low-endemic settings using a combination of community prevalence and health facility data. PLOS ONE. 2012;7:e42861.

54. Boyce RM, Reyes R, Matte M, Ntaro M, Mulogo E, Lin FC, et al. Practical Implications of the non-linear relationship between the test positivity rate and malaria incidence. PLoS ONE. 2016;11:e0152410.

\section{Submit your next manuscript to BioMed Central and we will help you at every step:}

- We accept pre-submission inquiries

- Our selector tool helps you to find the most relevant journal

- We provide round the clock customer support

- Convenient online submission

- Thorough peer review

- Inclusion in PubMed and all major indexing services

- Maximum visibility for your research

Submit your manuscript at www.biomedcentral.com/submit
() Biomed Central 